\section{Aviation Security and Terrorism: A Review of the Economic Issues}

\author{
Cletus C. Coughlin, Jeffrey P. Cohen, and \\ Sarosh R. Khan
}

"Protecting this system demands a high level of vigilance because a single lapse in aviation security can result in hundreds of deaths, destroy equipment worth hundreds of millions of dollars, and have immeasurable negative impacts on the economy and the public's confidence in air travel."

-Gerald L. Dillingham, United States General Accounting Office, in testimony before the Subcommittee on Aviation, Committee on Commerce, Science, and Transportation, U.S. Senate, April 6, 2000

T he terrorist attacks exploiting weaknesses in U.S. aviation security on September 11, 2001, did indeed produce the catastrophic results identified in the prophetic testimony cited above. ${ }^{1,2}$ Immediately after the attacks, security issues rose to paramount importance in the nation's policy agenda. ${ }^{3}$ Despite general agreement on what aviation security entails and the goals of an aviation security system, public controversy abounds on how to regulate and provide this important activity.

If airplanes and passengers, as well as property and people on the ground, are to be protected, potential perpetrators of aviation terrorism must be prevented from breaching security checkpoints and gaining access to "secure" airport areas and to aircraft. Given the interconnectedness of the air transportation system, a sufficiently high level of security must be provided throughout the entire system. Flexibility to respond quickly to new information about aviation security threats is a must. Moreover, incentives must be offered to both the regulators and security providers so that aviation security improvements can be devised and imple-

Cletus C. Coughlin is deputy director of research at the Federal Reserve Bank of St. Louis, Jeffrey P. Cohen is an assistant professor of economics at the Barney School of Business of the University of Hartford, and Sarosh R. Khan is a research associate at the Federal Reserve Bank of St. Louis. The authors thank Steven A. Morrison and Eran Segev for helpful comments.

(c) 2002, The Federal Reserve Bank of St. Louis. mented. At the same time, however, the costs associated with providing security must be incorporated in the decisionmaking process and weighed against the benefits.

In this paper we examine the economic issues relevant to airline and airport security in the United States, a topic that has received little attention from economists. Understanding the key economic issues is crucial in evaluating the various methods of regulating and providing aviation security and for appraising the conflicting positions over the appropriate scope of governmental involvement in this effort.

We begin our examination of the economics of aviation security by highlighting the key features of the airline industry, one of which is its network structure. As a result, security at one airport can affect security elsewhere-an example of a network externality. ${ }^{4}$ Next, we use elementary economics to show that unregulated private markets will likely provide too little aviation security, which sets the stage for an examination of the alternatives for regulating and providing aviation security. We review the key features of the recently passed Aviation and Transportation Security Act and the characteristics of the resulting security policy. A summary of our major points completes the paper.

\footnotetext{
1 Four planes were hijacked by 19 terrorists on September 11, 2001. Two of the flights-American Airlines flight AA 11 and United Airlines flight UA 175-departed from Boston's Logan International Airport. The former flight crashed into the north tower and the latter into the south tower of the World Trade Center. The third flight-American Airlines flight AA 77-departed from Washington's Dulles International Airport and ultimately crashed into the western side of the Pentagon. The fourth flight-United Airlines flight UA 93-departed from Newark International Airport. Following passenger actions against the hijackers, it crashed in Stony Creek Township in Pennsylvania. The hijackings led to the deaths of more than 3,000 people, including all the passengers and crew on the four flights.

2 We distinguish between aviation security and aviation safety. Aviation security issues require a perpetrator whose malicious intent is to advance his/her interests or that of a group, quite possibly by destroying lives and/or property. Aviation safety issues arise because of accidents due to human errors and mechanical failures.

3 Aviation security is part of the larger issue of transportation security, which, in turn, is part of homeland security. Security policies in the United States, as well as elsewhere, have effects throughout the world. See Flynn (2000) for a recommendation that U.S. transportation policymakers pay increased attention to U.S. vulnerabilities and Flynn (2002) for a discussion of the globalization issues associated with security policies.

4 An externality, also termed a spillover, is said to exist when either the consumption or production activity of one consumer/firm affects directly either the utility or production activity of an external party. In other words, some benefits or costs are experienced by a party that is not part of a specific consumption or production decision. The crucial economic feature of an externality is that its benefits or costs
} are not reflected in market prices. 


\section{Figure 1}

\section{The Lambert St. Louis International Airport Hub and Spoke System as of 12/12/01}

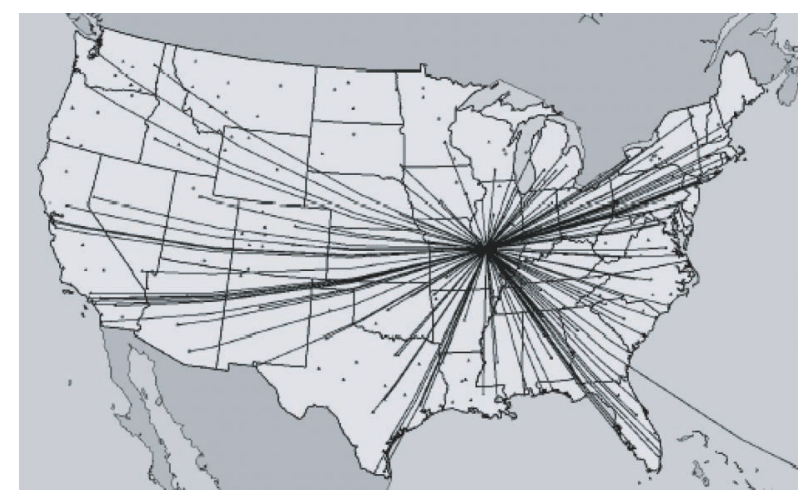

SOURCE: U.S. Department of Transportation, Bureau of Transportation Statistics.

\section{OVERVIEW OF THE AIRLINE INDUSTRY ${ }^{5}$}

Prior to 9/11 the air transportation sector accounted for approximately 1 percent of U.S. employment. In 2000 there were 14 "major" certified carriers in the U.S. airline industry. Total employment (including both full time and part time) in the major carrier group was about 672,000. The major passenger carriers with the highest number of total employees were American and United, each with slightly over 100,000. Although our primary focus is on the passenger carriers, freight transport is a significant factor for several reasons. A security breach at any one airport will undoubtedly affect the smooth movement of freight through the network as well. Federal Express, one of the 14 major carriers, employed more workers than either American or United. Freight revenues overall comprise about 10 percent of total operating revenues for the major carriers, with operating revenues exceeding \$20 million for each carrier. Finally, the recently passed legislation states that cargo as well as passengers will need to be screened.

\section{Airports and Airlines: The Hub and Spoke System}

Airports are a crucial component of the physical infrastructure for the airline industry. The United States has over 18,000 airports, 3,304 of which are eligible to receive federal funding. Approximately 430 airports are designated as "primary" airports by the Federal Aviation Administration (FAA). These primary airports handle virtually all the scheduled passenger service in the United States.

Subsequent to the deregulation of the airline industry that was propelled by legislation in 1978, many of the major U.S. airlines developed a "hub and spoke" system. With this structure, passengers on airline flights from various remote airports (the nodes on the spokes) converge on a single airport (the hub). After providing sufficient time for passengers to make their connections by changing planes, they depart for their final destinations. This interconnectedness is apparent in Figure 1, which shows the routes connected with the St. Louis hub. The picture would look similar for other hub cities. ${ }^{6}$

This hub and spoke system leads to interdependencies that give rise to several possible externalities. Namely, delays at one node often cause additional delays throughout the entire system. Thus, delays through one particular city due to security breaches can cause further delays at other nodes. For example, after a recent security breach at Atlanta's Hartsfield International Airport, an article in the Atlanta JournalConstitution reported: "Hundreds of flights around the country were canceled or delayed... [and] dozens of planes heading to Atlanta were diverted to other airports."7 Thus, by reducing travel delays throughout the system, improvements in security screening at a single airport can be viewed as a good (technically, a service) with spillover benefits. ${ }^{8}$ Furthermore, security improvements at one node in the network can result in an increased feeling of safety perceived by passengers at other nodes. In fact, this additional safety can accrue to those who are not even traveling, such as individuals who work in high rise office buildings or in any other potential target of an airline terrorist attack.

\section{9/11 and Airline Passenger Travel}

The events of 9/11 curtailed airline travel in various ways. First, these events reduced the demand

\footnotetext{
5 See O'Connor (2001) for a more comprehensive discussion of the economics of the airline industry.

6 See Shy (2001) for a theoretical exposition on the development of the hub and spoke system.

7 See Hansen and Tamman (2001, p. A.1).

8 Despite focusing most of our discussion on passengers, we recognize that rapid deliveries of freight-U.S. mail, checks for the Federal Reserve System, transplant organs, automobile parts, etc. - - have important economic effects.
} 
for air travel as a result of the increased concerns about safety. Second, these events reduced air travel by exacerbating the mild recession that began in March 2001. Third, the cost of travel was effectively increased because of the necessity of arriving earlier for departures, the increased frequency of delays resulting from security breaches, and new security surcharges. The result was substantially less air travel for both work and leisure purposes.

Figure 2 illustrates the dramatic drop in air passenger travel. In terms of revenue passenger miles, traffic during September 2001 declined more than 30 percent from the previous September. Despite some recovery during the fourth quarter of 2001, revenue passenger miles were down 15 percent year-overyear in December 2001. For the first five months in 2002, revenue passenger miles were 10 percent below the level in 2001. What is unclear is how long this shock will continue to affect passenger travel. Obviously, one of the major uncertainties is the effect of the new environment involving aviation security. ${ }^{9}$

\section{PROVIDING THE RIGHT AMOUNT OF AVIATION SECURITY - IN THEORY}

In our introductory comments, we noted that unregulated private markets were unlikely to provide adequate aviation security. We can illustrate this claim in a relatively straightforward manner by using a supply and demand diagram. Assume that, similar to the case in the United States prior to the events of 9/11, airlines are ultimately responsible for aviation security. Assume further that consumers of airline services have a demand for this type of security, which is admittedly difficult to measure, that can be represented by the demand curve, $D_{p}$, in Figure $3 .{ }^{10}$ The negative slope of the demand curve reflects the fact that, as the price of aviation security declines, the quantity of security that consumers desire increases. This demand curve reflects the marginal private benefits of aviation security. The supply curve for aviation security is represented by $S_{p}$ in Figure 1. The positive slope indicates that increases in security can be provided only by incurring higher per-unit costs, which reflects the notion of increasing opportunity costs. The intersection of these curves generates the quantity of this good, $Q_{p}$, that is likely to be provided in equilibrium by private markets. This quantity, however, is unlikely to be the optimal (or efficient) amount of aviation security. ${ }^{11}$

The primary reason for underprovision in this example is that there are likely to be important benefits from aviation security that extend beyond

\section{Figure 2}

\section{Air Traffic: System Revenue Passenger Miles}

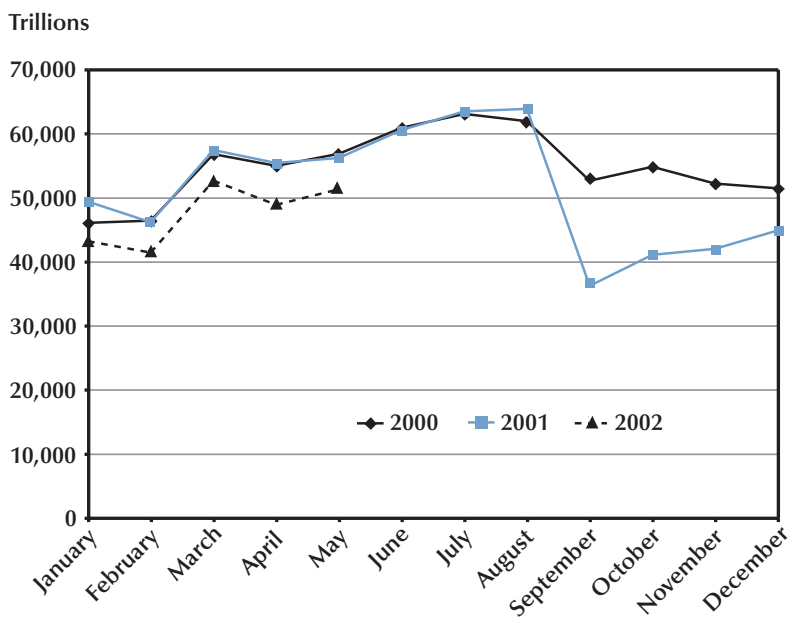

SOURCE: Air Transport Association.

the passengers who are on a flight. An especially gruesome example was provided by the events of $9 / 11$. Occupants of high-rise buildings as well as those occupying other potential targets for terrorist acts (e.g., nuclear power plants and government buildings) can benefit from aviation security and, in fact, the benefits can extend beyond those individuals to their families and much further. Economists refer to this scenario as a positive externality. If positive externalities, also termed spillover benefits, exist, then the social demand for aviation security

9 A number of incidents since $9 / 11$ have increased the fear of flying for some people. On November 4, 2001, screeners at O'Hare International Airport let a passenger with seven knives, a stun gun, and pepper spray pass through a checkpoint. On December 22, 2001, Richard Reid boarded an American Airlines flight at Charles deGaulle Airport in Paris. During the Miami-bound flight, he was overpowered by flight attendants and passengers as he tried to ignite the explosives contained in his shoes. See McTague (2002) for additional examples.

${ }^{10}$ Aviation security is simply one of the many attributes of air transportation service. As Moses and Savage (1990) stressed with respect to aviation safety, aviation security is not easily measured. For our purposes, we assume that a well-defined measure for safety exists that can be thought of in the following way: the smaller the probability that an airline flight will be disrupted maliciously, the larger the amount of aviation security.

11 Based on Coase's theorem, private markets might provide the efficient quantity even when externalities exist. Provided that there are no transaction costs and given that property rights are well defined and enforceable, Coase's theorem reveals that market incentives would exist for mutually beneficial trades so that the efficient output would result. In the present case, the conditions for the Coase theorem are unlikely to exist. See Cooter (1987) for a discussion of this theorem. 


\section{Figure 3}

\section{The Optimal Quantity of Aviation Security}

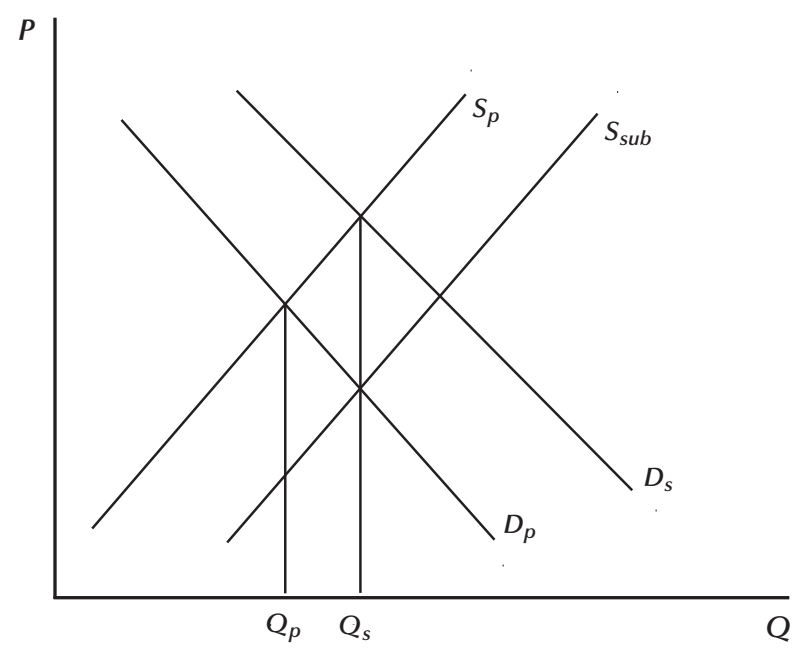

diverges from the private demand. This social demand encompasses the private demand plus the demand of those who benefit, but are not flying. ${ }^{12}$ This demand curve, $D_{s}$, lies above and to the right of the private demand. The intersection of this demand curve and the supply curve determines the efficient quantity of aviation security. As Figure 3 shows, this quantity, $Q_{s}$, exceeds the quantity that would be provided by private markets. ${ }^{13}$

An important issue here is how to induce an increase in security from $Q_{p}$ to $Q_{s}$, which leads to questions about the potential role of governmentgovernment regulation, provision, and subsidies are all possibilities. ${ }^{14}$ Figure 3 also illustrates the effect of a subsidy. A subsidy effectively lowers the cost per unit of security and, thus, can be represented by a downward (rightward) shift of the supply curve. Assuming that the optimal subsidy is provided, this new supply curve, $S_{\text {sub }}$, intersects $D_{p}$ at the point where the quantity of security is the socially desirable amount, $Q_{s}$. However, if the optimal subsidy is not provided, then either too little or even too much security is possible.

\section{AVIATION SECURITY PRIOR TO 9/11}

Historically, aviation security has been provided by three main partners: airlines, airports, and the FAA. Generally speaking, providing security has been the responsibility of air carriers and airports. Government, via the FAA, performed primarily a regulatory role.
The airlines were responsible for passenger and baggage screening, both carry-on and checked. The usual practice was for airlines to contract with private companies who provided trained screeners at security checkpoints. The airlines were also responsible for security from the screening checkpoints to the aircraft. Airports were responsible for law enforcement and general security in the airport vicinity, including exterior areas, parking areas, the airport perimeter, and interior areas up to the security checkpoints. The airports also hired law enforcement officers for the security checkpoints. The FAA was responsible for providing threat information; establishing security policies, regulations, and protocols; conducting security audits of airlines and airports; supporting research and development of security technology; and overseeing the installation of security equipment and devices in airports.

\section{Aviation Security Issues}

Even without factoring in the unpredictable nature of terrorism, the size of the U.S. air transportation system and the differences among airlines and airports suggest that providing aviation security is a complex and difficult task. Studies and legislation throughout the 1990s identified problems with aviation security and attempted to improve it. ${ }^{15}$ The bombing of Pan Am Flight 103 led to the passage of the Aviation Security Improvement Act of 1990. This legislation raised employment, education, and training standards for screeners and other airport security personnel. In 1996, the crash of TWA Flight 800 led to the creation of the White House Commission on Aviation Safety and Security. This group recommended the use of new screening technologies and equipment as well as the development of

\footnotetext{
12 Using standard terminology, the marginal social benefit, $D_{s}$, equals the marginal private benefit, $D_{p}$, plus the marginal external benefit. See Besanko and Braeutigam (2002, p. 744) for a more detailed illustration of the optimal subsidy when a positive externality exists.

13 Despite the likelihood that private markets will underprovide aviation security, it is possible that private markets might overprovide it. Aviation security is not easily observed by consumers. Because of an information imperfection, consumers might overestimate the security threat. As a result, the demand curve might be too far to the right, leading to an excessive provision of security.

${ }^{14}$ Note that in our illustration the private costs of providing security include all the costs of providing security. Thus, the private costs are equal to the social costs. In a later example, we focus on how externalities associated with the network of airline transportation affect the supply of aviation security.

${ }^{15}$ See U.S. General Accounting Office (2000a).
} 
uniform performance standards for training and testing screeners. Congress also passed legislationthe Federal Aviation Reauthorization Act of 1996 and the Omnibus Consolidated Appropriations Act of 1997-that provided funding for implementing many of the Commission's recommendations. For example, over the four years prior to 2000, Congress provided the FAA with $\$ 1$ billion for security. Roughly one-third of this funding was for the purchase and deployment of security equipment at airports. Finally, the Airport Security Improvement Act of 2000 required additional actions to improve aviation security.

The preceding studies and legislation highlighted numerous specific problems with aviation security. Problems existed in three major areas: aviation computer security; access to aircraft, airfields, and other facilities; and the detection of dangerous objects.

With respect to aviation computer security, two major problems were well known. One problem involved the physical security at facilities housing air traffic control systems. A General Accounting Office (GAO) study (2000b) reported in 1998 that most facilities (87 of 90) had not performed threat analyses for the air traffic control systems in the five years prior to the review. A second problem involved the management of security for operational computer systems. As of December 1999, the FAA was violating its own security requirements by failing to conduct background searches on contractor employees who were reviewing and repairing critical computer system software. These employees possess critical knowledge that could prove to be very useful for computer hackers. If hackers were to penetrate the air traffic control system, they could attack the computer systems used to communicate with and control aircraft. It is not hard to imagine the physical and economic problems of a successful attack.

With respect to access to aircraft, airfields, and other facilities, controls for limiting access to secure areas had not worked as intended. For example, the results of tests during 1998 and 1999 revealed that the Inspector General's staff of the Department of Transportation successfully gained access to secure areas 68 percent of the time. These results stimulated improvements; however, additional testing between December 1999 and March 2000 revealed a rate of unlawful access of 30 percent.

The problem area that has attracted the most attention involves the detection of dangerous objects. An increase in hijackings prior to 1972 stimulated the development of passenger-screening require- ments. The goal was to identify passengers carrying metallic weapons that could be used to hijack an airplane. With respect to passenger screening, personnel issues have received the most attention because screeners are not adequately detecting dangerous objects. Three reasons have been provided for this poor performance: inattention to training, high turnover, and low pay.

The previously cited GAO report revealed that the FAA was two years behind schedule in issuing a regulation implementing a congressionally mandated requirement to certify screening companies and improve the training and testing of screeners. All passengers and their carry-on baggage must be checked for weapons, explosives, or other dangerous articles that could pose a threat to the safety of the aircraft or those who board it. Until recent legislation was enacted, the FAA and air carriers shared this responsibility. The FAA set the screening regulations and established the basic standards for the screeners, the equipment, and the procedures to be used, while the air carriers were responsible for screening passengers and their baggage prior to their entry into secure areas or onto an aircraft. Generally, air carriers hired security companies to do the screening.

Concerns about the effectiveness of screeners have existed for many years. A GAO report (2000a) noted that, in 1978, screeners were not detecting 13 percent of potentially dangerous objects that FAA agents carried through checkpoints during tests. In 1987 , tests revealed that 20 percent of potentially dangerous objects were passing undetected through checkpoints. Despite features of the Federal Aviation Reauthorization Act of 1996 that attempted to increase the effectiveness of screeners and the screening process, recent testimony by a GAO official (2000b) stated that the performance of screeners remained a problem. Based on the FAA's test results, which cannot be released to the public, the GAO official concluded that screeners' ability to detect dangerous objects was not improving and, in some cases, was deteriorating.

High turnover of airport security personnel is a well-known problem. From May 1998 through April 1999, turnover averaged 126 percent at 19 large airports. Skilled and experienced screeners are rare. High turnover is attributed to low wages (frequently near minimum wage), low benefits, and job stress. With respect to wages, the GAO noted that starting wages at airport fast-food restaurants frequently exceeded those of screeners. 
In addition, there are some human factors associated with screening that contribute to poor performance. Screening requires repetitive tasks as well as intense monitoring for the very rare event when a dangerous object might be observed. To improve performance, the FAA began a number of programs, including establishing a threat image projection system to keep screeners alert and to monitor their performance; a screening company certification program; and screener selection tests, computer-based training, and readiness tests. However, the GAO found that the FAA's implementation was behind schedule.

The poor performance in the United States led the GAO to study screening practices in five other countries. They found lower turnover as well as differences in four areas. First, screening operations tend to be more stringent. Second, screeners' qualifications are more extensive. Third, screeners receive better pay and benefits. Fourth, responsibility usually resides with the airport's management authority or the government. Of 102 other countries with international airports, only Canada and Bermuda place responsibility with air carriers. Unfortunately, little information is available on performance; however, one joint test with another country revealed that the other country's screeners detected twice as many objects as the screeners in the United States.

\section{Technology Issues}

In addition to the personnel issues involved in detecting dangerous objects, there are technology issues. The technical performance of existing machines, which scan for metal objects, might not be adequate to detect the numerous dangerous objects that do not contain metal. A criticism of those providing aviation security is that they have failed to utilize available technology. Atkinson (2001) argues that numerous superior information technologies could and should be applied to increase aviation security. At the same time, however, the consideration of technical solutions requires the consideration of many nontechnical issues that can affect whether the technology can be implemented successfully.

New scanning technology can do a better job than the existing machines that scan only for metal. Many security experts are pushing for the use of screening machines capable of detecting a broader range of metals and alloys, plastic explosives, and other materials.

Experts are also pushing for the increased use of biometrics. Biometrics technology uses unique biological data to identify and authenticate an indi- vidual almost instantaneously. Various biological data, such as fingerprints, facial geometry, hand geometry, retinas, and voice patterns, can provide the necessary information. Plus the technical application of biometrics to increase aviation security is reasonably straightforward. For example, after background checks, an employee, such as a pilot, could be issued a card with his unique biometric information embedded on a computer chip with encrypted software. Entrance to a secure area, such as the cockpit, would require the pilot to put his card in a slot and submit to a biometric identification process to ensure that the card and the person holding it match.

A similar procedure could be used for passengers. The screening could take place both prior to entering the gate concourses and upon entering the boarding ramp to the plane. The latter authentication would allow accurate passenger manifests in real-time. This would enable airline personnel to identify individuals who have checked in, but not boarded. A related feature of this system would allow airlines to match passengers with their luggage. Luggage for an unboarded passenger could be removed.

The use of biometrics can be extended beyond the preceding examples. For example, facial biometric systems can scan individuals in a crowd or as they pass through a security checkpoint. Within seconds, a scanned face can be compared with a database of criminals or suspected terrorists. Obviously, the creation of such a database would require the cooperation of law enforcement agencies nationally as well as internationally.

The use of sophisticated technology is not simply a technology issue. In assessing the costs and benefits of using new technology, various nontechnical issues arise that can affect whether a specific technology should be utilized. First, health issues arise because the use of a technology embedded in a machine, especially one that emits radiation, might harm some individuals. Even the (inaccurate) perception that a machine might be dangerous could create adverse economic effects for the airline industry.

Second, the use of technology requires the consideration of legal and privacy issues. The technology could violate an individual's guarantee against unreasonable searches. Even if the search is legal, some potential travelers might be deterred because they feel uncomfortable with some personal information no longer being private. Understandably, many are concerned about scans that produce images 
of their bodies. According to Atkinson, the new scanning technology need not reveal physiological details that create privacy concerns for passengers.

Finally, the operation of machines raises space issues because of their size and the resulting lines of passengers. Moreover, airlines are concerned about maintaining their flight schedules and the inconveniences experienced by passengers. In certain cases, it is possible that the technology can assist airlines in meeting their schedules and increase passenger convenience. To date, it appears that the greater the security threat, the greater tolerance passengers have of inconvenient procedures that increase their security.

\section{AVIATION SECURITY IN THE AFTERMATH OF 9/11}

The events of 9/11 forced public decisionmakers to examine how aviation security was being provided and how to improve it. ${ }^{16}$ Generally speaking, three primary options for screening passengers and controlling access to secure areas were proposed before 9/11, although shortly thereafter attention focused primarily on how to implement the third option listed below. For each option identified by the GAO (2001), an underlying assumption was that the FAA would continue to regulate screening, oversee performance, and impose penalties for poor performance. These security management and provision options are as follows:

1. continue with the responsibility assigned to air carriers but with new requirements,

2. assign the responsibility to airports, or

3. assign the responsibility to the federal government via creation of a new federal agency (for example, a new agency within the Department of Transportation) or a federal corporation (for example, a corporation similar to the Tennessee Valley Authority).

\section{Option One}

The first option is the same as the pre-9/11 arrangement with the FAA promulgating new requirements. As we highlighted previously, unregulated private markets will likely provide too little aviation security. The events of 9/11 indicated that even with regulation by the FAA, too little aviation security was being provided; however, the events do not necessarily eliminate this option.

Continuing with this option implies that this system is the best way to provide aviation security.
One can argue that this option worked for a number of years. The pre-9/11 security arrangements date from the early 1970s and hijackings went down markedly after these arrangements were put in place. Obviously, the hijackings of 9/11 occurred, but it is not clear that any of the options under consideration would have prevented them. It is not clear that these hijackings would have been prevented if airport security personnel were federal employees rather than privately contracted personnel. In fact, federal rules as of 9/11 would have allowed the hijackers' knives and box cutters on board because the blades were shorter than four inches. Thus, detection might not have mattered. Nor is it clear that a federal force would prevent potential hijackers from entering secure areas any better than a private force. Moreover, in light of the GAO reports cited previously, the shortcomings in the performance of the FAA justify some caution in providing more authority to a governmental body.

One can argue that the events of 9/11 revealed only that the security threat was much greater than anticipated. Furthermore, one can argue that this underestimation of the threat was not the fault of the FAA, but rather of the intelligence community at large. Of course, apart from this failure to fully recognize the security threat, our prior discussion identifying specific security shortcomings revealed that this security management and provision option, while possibly the best, is far from ideal.

As mentioned previously, this option is utilized infrequently outside of the United States. Only 2 of 102 other countries with international airports had airlines handling the security function. The primary rationale for excluding airlines from the security function was the concern that airlines would focus unduly on lowering costs and providing passenger convenience and, therefore, shirk on providing safety.

\section{Option Two}

The second option, which excludes airlines from the security function, involves assigning the

\footnotetext{
${ }^{16}$ Our analysis focuses on the legislated changes in aviation security rather than the changes implemented shortly after 9/11. The latter changes have not eliminated aviation security problems. Incidents reported by McTague (2002) as well as a study conducted between September 11, 2001, and February 17, 2002, reveal the continuation of problems. Morrison (2002) reported that the Department of Transportation's inspector general found that screeners missed guns 30 percent of the time, knives 70 percent of the time, and simulated explosives 60 percent of the time. In addition, in 158 tests, undercover investigators boarded 58 aircraft at 17 of the 32 airports tested and accessed the tarmac 18 times. Thus, security was breached in 48 percent of the tests.
} 


\section{Table 1}

\section{A Game Theory Example of Airport Provision of Security}

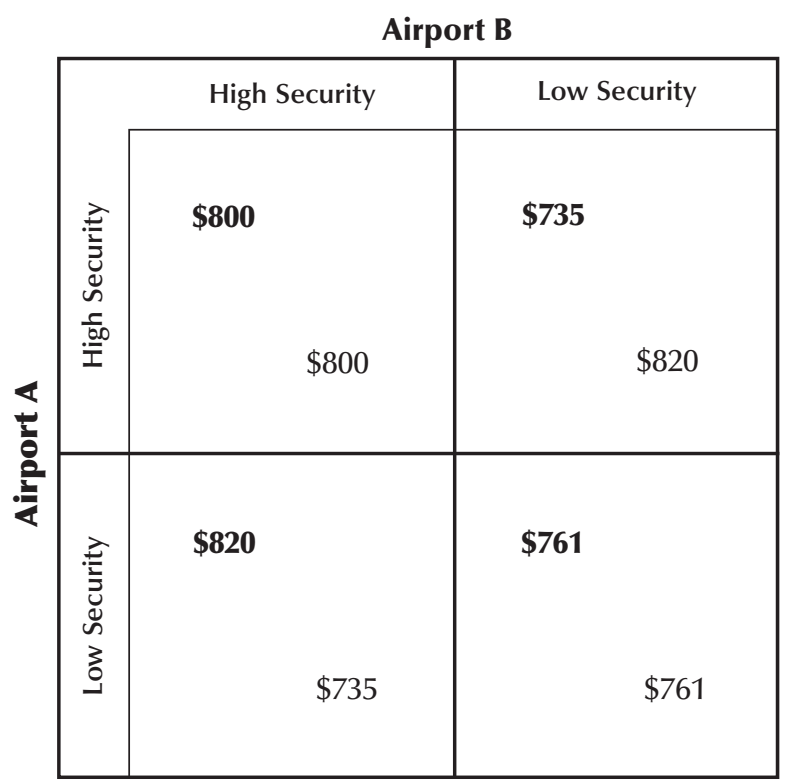

NOTE: Payoffs in bold are for Airport A.

security responsibilities to airports. A simple example using game theory can be used to model the network aspects of aviation security. Assume two airports - A and B-and two levels of aviation security - high and low. ${ }^{17}$ We can think of the high level of security as allowing air travelers to have more confidence that their flight will be safe than if a low level of security were provided. In other words, the higher level of security reduces the probability of successful terrorist attempts. Table 1 shows the hypothetical payoffs of each level of aviation security for each airport. For example, the payoffs for airports A and B when A provides low security and B provides high security are $\$ 820$ for $A$ and $\$ 735$ for $B$.

The economics underlying the payoffs in Table 1 require some elaboration. ${ }^{18}$ Assume that the profits (payoffs) of each airport are $\$ 1000$ prior to any security expenditures or any losses stemming from successful terrorist attacks. The expense of providing a high level of security is $\$ 200$, while the expense of providing a low level of security is $\$ 50$. Assume further that a successful act of terrorism imposes a cost of $\$ 1300$ at the airport where the act occurs. If both airports provide a high level of security, acts of terrorism are prevented. If one airport provides a high level of security and the other provides a low level, then a successful terrorist act can occur at either airport; a successful terrorist act damaging the high-security airport would have emanated from the low-security airport. ${ }^{19}$ Assume the probability of a successful terrorist act is 0.1 at an airport providing a low level of security and that the probability is 0.05 that the successful terrorist act, whose roots can be traced to the airport providing a low level of security, occurs at the other airport.

These assumptions produce the payoffs in Table 1. In the first arrangement, assume both airports provide a high level of security; both airports then receive a payoff of $\$ 800$, which is simply $\$ 1000$ less the $\$ 200$ expense of providing a high level of security. There are no other cost calculations for this arrangement.

In the second arrangement, assume airport $A$ provides a high level of security and airport B provides a low level of security. The payoff for airport $A$ is $\$ 735$ : Starting from $\$ 1000$, this airport incurs the $\$ 200$ expense of providing a high level of security and an expected loss of $\$ 65$. (The latter expense is the cost of a successful terrorist act [\$1300] times the probability that it occurs at airport A [0.05]). Meanwhile, the payoff for airport B is $\$ 820$ : Starting from $\$ 1000$, this airport incurs the $\$ 50$ expense of providing a low level of security and an expected loss of $\$ 130$. (The latter expense is the cost of a successful terrorist attack [\$1300] times the probability that it occurs at airport B [0.1]). Thus, if one airport provides a high level of security and the other airport provides a low level of security, the payoff for the first airport is $\$ 735$ and the payoff for the second airport is $\$ 820$.

In the third arrangement, assume both airports provide a low level of security; they would each receive a payoff of $\$ 761$. Starting from $\$ 1000$, each airport incurs the $\$ 50$ expense of providing a low level of security as well as two expected losses. The first is the $\$ 130$ loss associated with a successful terrorist act occurring due to the airport's own low level of security and the second is a $\$ 59$ loss (rounded from $\$ 58.50)$ due to the other airport's low level of

\footnotetext{
17 This game theory framework can be extended to a case in which three or more airports provide security, but the basic economic insights are unchanged by increasing the complexity.

18 A similar example can be found in Kunreuther and Heal (2002); however, their focus is on airlines providing security, whereas we concentrate on a network of airports that provide security.

${ }^{19}$ Kunreuther and Heal (2002) refer to these cross-effects as contamination.
} 
security. (This latter loss is calculated by multiplying $\$ 65$-that is, the cost of low security at one airport resulting in costs borne by the other airport-by 0.9 , which is 1 minus the probability that the successful terrorist act occurred at the airport where the terrorism emanated.)

Given the preceding payoffs, what levels of security will likely be provided by the airports? Assuming that the airports make their security decisions simultaneously without communicating directly with each other, the answer is that both will provide the low level. The reasoning is straightforward. Assume airport B thinks airport A will provide the high level. If so, then if airport $B$ also provides the high level, the payoff for airport $B$ is $\$ 800$. If airport $B$ provides the low level, the payoff for airport B is $\$ 820$. Thus, airport $B$ will choose the low level of security because it provides the larger payoff. What happens if airport B thinks airport A will provide the low level of security? Once again, airport $B$ will choose to provide the low level of security because the payoff to airport B is larger with the low level of security (that is, $\$ 735$ versus \$761). Thus, regardless of what airport $A$ chooses, airport B will choose the low level of security. By the same reasoning process, airport A will choose the low level of security regardless of airport B's choice.

The so-called dominant strategy is for both airports to choose the low level of security. Note that the payoff for both airports is $\$ 761$ and that such a payoff is inferior to the payoff of $\$ 800$ to both airports if they had both chosen to provide the high level of security. Thus, when the airports choose their security level simultaneously without coordinating their decisions, there is a high probability that they will end up with lower security throughout the network. In addition, the airports will achieve lower payoffs than if they had coordinated their security decisions and jointly provided a high level of security. ${ }^{20}$

\section{Option Three}

The conclusion, similar to that of the first option where airlines were responsible for security provision, is that in a world in which each airport is left to provide security on its own without governmental intervention, underprovision of aviation security is likely. Thus, regardless of whether airlines or airports provide security, a role for the federal government as a regulator should not be seen as a contentious issue. Instead, the major choice for policymakers is whether the federal government of the United States should contract out the provision of aviation security services or whether it should provide those services in-house. The former scenario entails some form of public-private partnership handling aviation security. This became the norm in Western European countries during the 1990s when countries privatized aviation security following security failures by government-run operations. ${ }^{21}$ Under this scenario, the government sets the security standards and either assigns screening responsibilities to the airport authorities or hires firms directly. Regardless, the agent is held accountable for meeting the security standards. Under this third policy option, from the list at the beginning of this section, the government is assigned full responsibility for providing security. 22

Economic theory highlights a number of considerations regarding this third option relative to the first two options. The theory of fiscal federalism indicates the possibility of a tradeoff between (i) accounting for an externality by having a higher level of government involvement and (ii) allowing residents in individual jurisdictions to choose the desired level of public service for their own community. ${ }^{23}$ If the federal government were to take over the provision of security at an airport, then it would be able to account for the spillover benefits by providing a higher level of airport security. However, it might do so at the cost of preventing demand diversity from being satisfied at individual airports because

\footnotetext{
20 The numbers underlying the example were chosen to illustrate a point. It is possible that the dominant strategy could be providing a high level of security. A Nash equilibrium is also possible. In this case, an airport's best alternative depends on the security choice of the other airport. In addition, the results can be sensitive to whether the game is played just once or is repeated.

21 Lott views this privatization as very successful. He notes that there were 21 hijackings in European airports during the 1970s, 16 during the 1980 s, and 4 during the 1990s. Overall, only 3 of these 41 hijackings originated from airports with private security. Lott's argument can be found in an article on the American Enterprise Institute's Web site: < www.aei.org/oti/oti13442.htm >

22 The events of $9 / 11$ generated one other contentious issue regarding governmental involvement in the U.S. airline industry. The Air Transportation Safety and System Stabilization Act included an aid package for the airline industry totaling $\$ 15$ billion $-\$ 5$ billion in outright cash grants and $\$ 10$ billion in government-backed loans. Most agree with compensating airlines for their losses after being shut down because of the terrorist attacks. Yet, subsidies delay the adjustment of the airlines to the new economic environment. The Air Transport Stabilization Board was created to determine who receives loan guarantees and the terms. Those with a free-market orientation object because public sector employees rather than private decisionmakers are picking the winners and the losers, while those with an interventionist orientation fear that the airlines they favor will be at a disadvantage if they do not receive their fair share.

23 See Oates (1972) for additional discussion of fiscal federalism.
} 
the level of security is determined by the federal government. In many instances, individual communities might prefer less security at their airports than the level chosen by the federal government.

Economic theory also highlights a number of other potential problems with assigning security responsibilities to a federal agency. First, the public agency is a monopoly supplier. Similar to any monopolist, the public agency might not be forced by competitive pressures to ensure an efficient provision of services. In addition, because of civil service restrictions, the public agency might be faced with a labor environment that precludes efficient delivery of services. ${ }^{24}$ Moreover, public agencies are frequently characterized as being slow in adjusting to changed circumstances as well as being unlikely to innovate. ${ }^{25}$

Additional problems might arise because the public agency is likely judged primarily on its security record. Overprovision of aviation security is possible because government bureaucrats have an incentive to protect themselves from the damage that could result if too little security is provided. In this case, the agency will have an incentive to ignore the tradeoffs that occur between security and other attributes of air transportation services that consumers demand. ${ }^{26}$ For example, the public agency might tend to underestimate the cost of waiting incurred by passengers when it determines whether to institute a specific security measure. Waiting is a cost that airlines are sensitive to because of their profit incentive. On the other hand, the lack of a profit incentive when security is provided by the government might lead public managers to consider extended waits as simply an unavoidable cost of travel.

The fate of the following proposal, backed by the airline industry, might prove to be a good indicator of how responsive the public agency responsible for providing aviation security is to the economic interests of the airline industry. The proposal suggests creating a category of passengers known as "trusted travelers." To avoid some security checks at the airport, these travelers would endure background checks. The trusted travelers would each receive a special identification card that would allow them to proceed through a faster security line. A major concern is ensuring that the individual carrying the identification card is the trusted traveler. ${ }^{27}$

The heightened security measures implemented since $9 / 11$ have already produced some examples of what could be viewed as security considerations taking precedence over other attributes of air transportation services demanded by consumers. How- ever, one can also argue that the following examples are simply temporary costs associated with the transition to the new security environment. ${ }^{28}$ Between October 30, 2001, and February 4, 2002, there were 35 airport terminal evacuations. Between October 30, 2001, and December 31, 2001, a total of 1,361 flights were delayed, with a cumulative delay time of 2,173 hours. During this period, 587 planes were stopped and evacuated. 29

On the other hand, there are arguments supporting federal government provision of aviation security. First, as highlighted previously, the federal government can account for the spillover benefits associated with the provision of aviation security in its production decision. Second, governmental provision might be preferable to privatization because, relatively speaking, the former limits the incentives of managers to reduce quality by cutting costs. ${ }^{30}$ In other words, relative to managers in private firms, managers of a government operation have less incentive to reduce quality by cutting costs because of the relatively smaller financial gains for the public employees.

24 Glaeser (2001) shows that the more labor intensive the production process, the less desirable it is to nationalize the activity. Such a result could apply to airport security firms because the searching process is labor intensive. Glaeser argues that the intuition underlying his result is that when a firm is publicly owned, the workers tend to be paid in excess of the market-clearing wage rate. Thus, firms that are labor intensive are not suitable candidates for public ownership.

25 Lott, among others, makes these points. See < www.aei.org/oti/ oti13442.htm >

26 Holmstrom and Milgrom $(1991,1994)$ show that an agent with strong incentives to pursue one objective might well shirk on other objectives.

27 According to Branch-Brioso (2002), this proposal seeks a system similar to one used since 1998 at Ben Gurion Airport in Tel Aviv. Hand scans are used to match the traveler with the identification card. Roughly 120,000 Israeli citizens are enrolled travelers.

28 The examples can be found in Power (2002b).

29 The increased scrutiny of passengers by screeners has sparked a privacy debate. Privacy means different things to different individuals. In some cultures and religions, the act of removing a headcovering is considered the equivalent of a public strip search. The FAA has responded to several complaints by providing detailed guidelines on performing security checks on passengers who might consider screeners' requests too intrusive. See the FAA's Office of Civil Rights at <www.faa.gov/acr $>$. To complicate the matter even further, several instances of harassment and abuse have been reported, some by flight crew members, since the new security measures have taken effect. See Marks (2002) and Power (2002a) for details.

30 Hart, Schleifer, and Vishny (1997) show that if contracts are incomplete, the private provider has a stronger incentive to improve quality and reduce costs than a government employee has. However, the private provider's incentive to reduce costs is excessive because this provider ignores the adverse effects on quality that are not contractable. 
In the case of aviation security, a specific concern is that private providers hire unqualified screeners and guards to minimize their costs. These attempts to cut costs undermine aviation security throughout the air transportation network. Public provision tends to mitigate this problem. This advantage of public provision is likely more pronounced the more difficult it is to specify the quality of a service. Aviation security seems to be such a case.

\section{THE AVIATION AND TRANSPORTATION SECURITY ACT OF 2001}

The Aviation and Transportation Security Act was signed into law (Public Law 107-71) on November 19,2001 , by President Bush. The act is a comprehensive approach to increasing aviation security. The objective of the act is to create, develop, and streamline security procedures and protocols that radically reduce the chances of any security breach or violation.

The enactment of the Aviation and Transportation Security Act considerably alters the aviation security responsibilities of airlines, airports, and the federal government. In the context of the three GAO options discussed previously, this legislation is the third option. A substantial increase in the resources committed to aviation security will occur as well.

The act establishes the Transportation Security Administration (TSA) in the Department of Transportation (DOT). The TSA is to be headed by the Under Secretary of Transportation for Security. As of February 17, 2002, the TSA assumed the civil aviation security functions and responsibilities of the FAA. In addition, the legislation identifies some new aviation security responsibilities. The responsibilities of this office include coordinating and directing aviation security at all times and all domestic transportation security in case of a national emergency.

The most controversial feature of the legislation is the requirement that the Attorney General and the Secretary of Transportation develop a program that ensures the screening of all passengers and baggage for illegal and dangerous items. The Attorney General is given the responsibility to develop a work force of federal employees in accordance with the guidelines of the act. This work force, which will be implemented as workers become qualified, is expected to be fully deployed by November 19, 2002. The legislation stipulates that the screeners should be subjected to background checks and that they be U.S. citizens. The TSA is also charged with ensuring sufficient explosive detection systems to screen all checked baggage at U.S. airports by December 31, 2002.

This latter objective might prove to be especially hard to achieve, especially if passenger convenience is considered in the actions necessary to meet this objective. According to Spagat (2001), fewer than 150 luggage-scanning machines capable of detecting bombs and plastic explosives were in place at 47 U.S. airports at the end of September 2001. In addition to being costly - the initial cost is roughly $\$ 1$ million plus yearly costs of $\$ 700,000$ to $\$ 1$ million for operation and maintenance-these machines are currently slow and inaccurate. A scanner can handle only about one planeload of luggage per hour, and false alarms sound for roughly 22 of every 100 bags. Personnel must then open and search these bags. In addition, the machines can be as long as 16 feet, which poses the challenge of fitting them into existing spaces. Finally, producers of these machines might not be able to expand production rapidly enough to meet this objective. ${ }^{31}$

Another change is that air marshals may be deployed on all commercial flights. While the Attorney General is responsible for developing the air marshal program, the day-to-day administration of the program would be the DOT's responsibility.

Federal law enforcement officers will also be deployed to secure all areas in the larger airports, including the perimeter. A related requirement is for the DOT to improve access control systems and equipment for secured areas.

As part of a compromise to ensure passage of the legislation, the act allows for the following program. Depending on authorization by the Under Secretary of Transportation for Security, a small number of airports may employ the services of a qualified private company for the provision of airport security for up to three years. The legislation also allows other airports to opt out of the screening program and contract with private security providers after three years, if they so desire.

The legislation also contains a number of other noteworthy features. The legislation authorizes the DOT to reimburse airports for their additional costs

\footnotetext{
31 Spagat (2001) notes that the FAA had planned to wait until 2009 to phase-in requirements for scanning all checked bags for explosives. The events of 9/11 prompted the FAA to accelerate the phase-in to 2004 .
} 


\section{Table 2}

\section{The Cost of the Aviation and Transportation Security Act (millions of dollars)}

\begin{tabular}{|c|c|c|c|c|c|c|}
\hline & 2002 & 2003 & 2004 & 2005 & 2006 & Total \\
\hline Passenger and baggage screening & 889 & 1,942 & 2,181 & 242 & 0 & 5,254 \\
\hline Air marshals & 92 & 316 & 561 & 59 & 0 & 1,028 \\
\hline Airport security measures & 268 & 582 & 631 & 63 & 0 & 1,544 \\
\hline Reimbursement of airport authorities & 553 & 552 & 0 & 0 & 0 & 1,105 \\
\hline General aviation aircraft security & 19 & 41 & 45 & 4 & 0 & 109 \\
\hline R\&D chemical and biological weapons & 13 & 22 & 11 & 11 & 3 & 60 \\
\hline R\&D aviation security technology & 39 & 51 & 50 & 50 & 50 & 240 \\
\hline Regulations and reports & 2 & 1 & 0 & 0 & 0 & 3 \\
\hline Estimated total cost & 1,875 & 3,507 & 3,479 & 429 & 53 & 9,343 \\
\hline
\end{tabular}

SOURCE: Congressional Budget Office.

of complying with increased security measures in the aftermath of 9/11. The act expands the scope of the DOT's research and development activities related to aviation security. The act requires strengthening cockpit doors and raising the quality of screening. In addition, the act allows for the needs of small airports to be dealt with by the Attorney General's office on a case-by-case basis.

The key features of the legislation can be summarized by using a concept that economists refer to as a production function. A production function shows the relationship between output, which is aviation security, and inputs, which are productive resources. Using standard terminology, the production of aviation security requires labor, capital, and technology. The labor inputs take various forms, such as passenger and baggage screeners, law enforcement officers in airports and in airplanes, managers/ administrators, and researchers. The capital inputs are items such as passenger and baggage screening machines, access control systems for secured areas, and reinforced cockpit doors. Underlying the amount of output that can be produced by combining these labor and capital inputs is the level of technology, which is the body of available knowledge concerning how to combine inputs to generate maximum output. One way to increase knowledge that contributes to the increased production of aviation security is through the research and development efforts of researchers. Frequently, this new knowledge is embodied in machines and other productive resources.
Generally speaking, the legislation increases the labor and capital inputs devoted to aviation security; however, the availability of selected labor and capital inputs could prove to be a major obstacle in the near term. In addition, the legislation assigns control of these inputs to the federal government. The major unanswered question is whether the incentive system for government employees will lead to a better system in terms of the efficient production of the desired level of aviation security than any other system. Another question, somewhat easier to answer, is how much the preceding changes might cost.

\section{Estimated Federal Government Cost}

Table 2 shows a cost estimate of $\$ 9.4$ billion by the Congressional Budget Office (CBO) for the expenses of the federal government. ${ }^{32}$ The focus is on the changes in spending that are subject to appropriation for 2002-04.33 The funds would be used for paying expenses in the following categories: passenger and baggage screening, air marshals, airport security measures, reimbursements to airports stemming from the additional security expenses due to 9/11, general aviation aircraft security, research and development on chemical

\footnotetext{
32 The CBO's cost estimate dated October 26, 2001, was found at $<$ www.cbo.gov/cost.shtml > The bill number is S. 1447.

33 Because the appropriations will occur later, the actual expenses during 2005 and 2006 for selected categories, such as "passenger and baggage" and "air marshals," are understated substantially.
} 
and biological weapons, and research and development on aviation security technology. 34

Passenger and Baggage Screening. The $\mathrm{CBO}$ estimate assumed that the Attorney General would maintain a staff of screeners similar to the existing staff employed in the private sector and that this staff would increase to keep pace with increases in passengers on domestic flights. The existing staff in the private sector consisted of 16,200 screeners, 2,800 supervisors, and 100 managers. Based on the federal pay schedule the $\mathrm{CBO}$ estimated that the screeners would receive an average annual base salary of $\$ 35,500$, substantially higher than the average salary of screeners in the private sector of roughly $\$ 15,000$. To generate an estimate of the actual costs per screener, this average base salary was adjusted upward by benefits of 35 percent of the base as well as by overtime pay. The CBO estimates used an average salary of $\$ 52,600$ for supervisors and $\$ 74,900$ for managers. These salaries were adjusted for benefits identical to the screeners, but no overtime pay was anticipated.

The legislation also authorizes the Attorney General to deploy at least one law enforcement officer at each of the existing 754 airport checkpoints. Thus, at a minimum, to staff each checkpoint around the clock requires 2,262 officers. The Attorney General has the authority to deploy more officers at the 100 largest airports. The CBO estimates used an average salary of $\$ 46,500$ for these officers. Benefits plus overtime increase the average cost for each officer to $\$ 73,000$.

In addition to the personnel involved directly in screening and law enforcement, there are a number of other costs. First, there are expenses associated with the required administrative staff. Second, there are costs for training, testing, and auditing screeners and for performing background checks. Third, the legislation requires a senior level security officer at each airport (about 450 positions) and two ground security coordinators at each checkpoint (about 1,500 positions). Fourth, additional screening equipment must be purchased, installed, and maintained. The total costs for screening and law enforcement are estimated to be $\$ 5.3$ billion.

Air Marshals. The legislation authorizes the presence of air marshals on all scheduled flights. Whether or not an air marshal would fly on all scheduled flights is to be determined by the Attorney General. The CBO assumed that an air marshal would fly on 20 percent of all flights. 35 As a result, the number of required air marshals would be
2,800 . The CBO estimated an average cost per marshal, including salary, benefits, training, supervision, equipment, and other administrative expenses, of $\$ 170,000$ and a total cost of $\$ 1$ billion.

Airport Security Measures. The legislation authorizes a variety of measures estimated to cost $\$ 1.5$ billion to increase security at airports. First, the legislation authorizes the deployment of federal law enforcement officers to secure all areas in the nation's largest airports. Second, the Secretary of Transportation is to work with small- and mediumsized airports to determine their needs. This might lead to the deployment of federal law enforcement officers in these airports as well. Third, the Secretary of Transportation is to work with airport operators to improve access control systems and equipment for secured areas.

The CBO estimates that 6,990 federal law enforcement officers would be deployed at an average cost per officer of $\$ 85,000$. Each of the 120 largest commercial airports would have 50 federal law enforcement officers. On average, the smaller airports would have three federal law enforcement officers.

Reimbursement of Airports for Increased Security Costs. The legislation authorizes the Secretary of Transportation to reimburse airports for their fiscal year 2002 costs associated with complying with the 9/11-induced security measures. The costs cover additional law enforcement personnel, access-control equipment, and operating costs. Some of these upgrades will not be completed in 2002 , so roughly one-half of the $\$ 1.1$ billion cost will be incurred in 2003.

General Aviation Aircraft Security. The legislation requires the FAA to develop a program to search general aviation aircraft (i.e., private aircraft and charter planes) as well as screen crew members and others who might board a flight prior to takeoff. The CBO estimates the cost of this security enhancement to be $\$ 109$ million for the 2002-04 period.

Research and Development. The legislation authorizes the FAA to expand research in two areas. First, the FAA is authorized to conduct research concerning chemical and biological warfare and

\footnotetext{
34 A final category involving regulations and reports is not discussed because of its small (less than $\$ 3$ million) budgetary effects.

35 McTague (2002) argues that two air marshals should be on each commercial flight in the United States. Since the Israelis began such a program in 1986, no El Al flight has been hijacked.
} 
to develop technologies to prevent the successful use of these weapons in planes and airports. Second, the FAA is to increase support for research and development related to all aspects of aviation security involving technology, such as detecting explosives; screening baggage, passengers, and cargo; training employees; and constructing aircraft. The FAA's support would be in the form of grants to industrial, academic, and governmental entities for promising projects. In addition, the FAA is authorized to provide research grants dealing with biometrics, longerterm airport security, and information sharing among federal agencies. In total, the estimated cost of research and development is $\$ 300$ million.

\section{Estimated Impacts on Non-Federal Governments and the Private Sector}

The legislation requires numerous actions by airport operators and, depending on how the FAA and Department of Justice choose to implement other requirements in the legislation, may necessitate other actions. In the former category are requirements that airport operators use technology to detect weapons, develop security awareness programs for airport employees, and conduct background checks on employees with access to planes and secure areas. In the latter category are requirements involving security around airport perimeters, the screening of passengers at smaller airports, and the screening of personnel and supplies entering secure areas.

Generally speaking, airport operators have already taken actions to comply with FAA regulations following $9 / 11$. The additional costs are not expected to exceed \$56 million annually (in 2001 dollars). Moreover, the legislation authorizes funding for airports to cover the costs of security improvements resulting from post-9/11 requirements.

With respect to the impact on the private sector, the legislation imposes mandates affecting air carriers, commercial airplane manufacturers, persons providing training in operating aircraft, and aliens. The Department of Transportation has imposed a \$2.50 fee for each passenger enplanement that will be remitted by the airlines to the federal government to pay for the federal government's costs of providing aviation security. Because air carriers would no longer be responsible for screening passengers and baggage, it is uncertain whether the net income of air carriers would rise or fall.

The bill requires commercial manufacturers to increase the security involving the doors separating the pilots from the passengers on new large aircraft as well as on new commuter aircraft. The cost of this mandate depends on the standards set by the FAA.

Finally, the legislation mandates that persons who provide aircraft training report certain information on those they train. Aliens would be required to undergo a background check from the Attorney General prior to training. The expectation is that the costs of these mandates would be small.

\section{CONCLUSION}

One unsettling conclusion following the events of 9/11 was that both the quantity and quality of aviation security, each difficult to measure, were inadequate. Quite likely both demand and supply factors underlie this conclusion. On the demand side, the catastrophic events of $9 / 11$ increased the demand for aviation security by increasing awareness of the very real security threat that existed and likely continues to exist. Moreover, the events of 9/11 focused attention on how aviation security was being provided and regulated. This attention revealed numerous shortcomings that prompted increased scrutiny of not only how much aviation security was being provided, but also how it was being provided.

Public decisionmakers have been prompted to ensure that more resources will be devoted to providing aviation security today as well as to research and development activities that should lead to improvements in aviation security in the future. In addition, changes were made in who has the authority concerning aviation security decisions. The hope is that these changes will result in the provision of the efficient level of aviation security.

Economic theory can be used to make a strong case that the federal government play an important role in aviation security. The basic question is whether the federal role should be restricted to setting and monitoring security standards or whether the role should also include the financing and implementation of security. The most contentious change emanating from $9 / 11$ is that the federal government has assumed responsibility from the airlines and airports for the actual provision of aviation security. Policymakers assigned the responsibility for aviation security to the federal government, primarily through the authority vested in the newly created Transportation Security Administration and the Department of Justice.

Will this substantial enlargement of governmental involvement, which is in contrast to the publicprivate partnerships that dominate aviation security 
in Europe, be a change for the better? In theory, public provision of aviation security can adequately account for security externalities. Moreover, relative to private provision, public provision reduces the incentives to reduce quality by reducing costs. Proponents of in-house provision argue that the quality of public services delivered by government employees is superior to that delivered by private firms. This feature of public provision might be especially relevant for a service, such as aviation security, whose quality is hard to observe.

On the other hand, a public agency might not provide security services efficiently because it can operate in a more-or-less monopolistic manner. Proponents of government contracts with private suppliers argue that private firms deliver public services at a lower cost than the government does. In addition, responsiveness to the consumer is not a trademark of monopolistic markets.

Furthermore, it is also possible that a public agency with one objective might provide an excessive amount of security (and incur excessive costs) because it is likely to be judged primarily on its security record and not on all the attributes encompassed by air transportation services for consumers. If either or both situations occur, then adverse consequences would result for both consumers and suppliers of air transportation services. At this point, given the still vivid memories of 9/11, the general public is likely to prefer too much aviation security to too little. However, one cannot conclude that public provision is a panacea.

The more important question is whether public provision will be an improvement relative to the less-than-perfect pre-9/11 system for providing aviation security. It is too early to answer this difficult question.

\section{REFERENCES}

Atkinson, Robert D. "How Technology Can Help Make Air Travel Safe Again.” Policy Report, Progressive Policy Institute, September 2001.

Besanko, David A. and Braeutigam, Ronald R. Microeconomics: An Integrated Approach. New York: Wiley, 2002.

Branch-Brioso, Karen. "U.S. Official Backs 'Trusted Traveler' Plan for Airports.” St. Louis Post-Dispatch, 23 April 2002, p. A3.

Cooter, Robert. "Coase Theorem," in John Eatwell, Murray Milgate, and Peter Newman, eds. The New Palgrave: A
Dictionary of Economics, Vol. 1, A to D. New York:

Macmillan, 1987, pp. 457-60.

Flynn, Stephen E. "America the Vulnerable." Foreign Affairs, January/February 2002, 81(1), pp. 60-74.

Century." TR News, November-December 2000, pp. 3-7.

Glaeser, Edward L. "Public Ownership in the American City." Working Paper No. W8613, National Bureau of Economic Research, December 2001.

Hansen, Jane O. and Tamman, Maurice. "UGA Fan's Hunt for Camera Bag Turns World's Busiest Airport into Haltsfield.” The Atlanta Journal-Constitution, 17 November 2001, p. A.1.

Hart, Oliver; Schleifer, Andrei and Vishny, Robert W. "The Proper Scope of Government: Theory and Application to Prisons." Quarterly Journal of Economics, November 1997, 112(4), pp. 1127-61.

Holmstrom, Bengt and Milgrom, Paul. "Multitask PrincipalAgent Analyses: Incentive Contracts, Asset Ownership, and Job Design." Journal of Law, Economics and Organization, Special Issue 1991, 7(0), pp. 24-52.

."The Firm As an Incentive System." American Economic Review, September 1994, 84(4), pp. 972-91.

Kunreuther, Howard and Heal, Geoffrey. "Interdependent Security: The Case of Identical Agents." Working Paper No. W8871, National Bureau of Economic Research, April 2002 .

Marks, Paul. "Flight Attendants Find Security Abusive." Hartford Courant, 18 February 2002.

McTague, Jim. “Wanted: Wyatt Earps.” Barron's, 4 March 2002, pp. 21-22.

Morrison, Blake. "Tests Show No Screening Improvements Post-Sept. 11.” USA Today, 25 March 2002, p. A4.

Moses, Leon N. and Savage, Ian. "Aviation Deregulation and Safety." Journal of Transport Economics and Policy, May 1990, 24(2), pp. 171-88.

Oates, Wallace E. Fiscal Federalism. New York: Harcourt Brace, 1972.

O'Connor, William E. An Introduction to Airline Economics. New York: Praeger, 2001. 
Power, Stephen. "Airport Screens Cause Conflicts with Carriers." Wall Street Journal, 22 February 2002a, p. A3.

. "Airlines and Stadiums Have Boosted Security, but Much Remains Undone." Wall Street Journal Online, 8 March 2002b.

Shy, Oz. The Economics of Network Industries. Cambridge: Cambridge University Press, 2001.

Spagat, Elliot. "Sophisticated Bag Scanners Fail to Catch On As Airlines Complain of Delays, False Alarms." Wall Street Journal Online, 29 October 2001.

U.S. General Accounting Office. Aviation Security: LongStanding Problems Impair Airport Screeners' Performance. Washington, DC: June 2000a.

Aviation Security: Vulnerabilities Still Exist in the Aviation Security System. Washington, DC: April 2000b.

Aviation Security: Weaknesses in Airport

Security and Options for Assigning Screening Operations, Testimony before the Subcommittee on Aviation,

Committee on Transportation and Infrastructure, House

of Representatives. Washington, DC: 12 September 2001. 